\title{
A Comprehensive Overview of Risk Scoring Systems for Predicting Intravenous Immunoglobulin (IVIG)- Resistance in Kawasaki Disease
}

\author{
Seiichiro Takeshita ${ }^{1 *}$, Takashi Kanai ${ }^{2}$, Yoichi Kawamura ${ }^{2,3}$ and Shigeaki Nonoyama ${ }^{2}$ \\ ${ }^{1}$ Division of Nursing, National Defense Medical College, Japan \\ ${ }^{2}$ Department of Pediatrics, National Defense Medical College, Japan
}

${ }^{3}$ Department of Pediatrics, Japan Self-Defense Forces Central Hospital, Japan

*Corresponding author: Seiichiro Takeshita, Division of Nursing, National Defense Medical College, Japan

\begin{abstract}
It is important to predict Kawasaki Disease (KD) patients who will be resistant to Intravenous Immunoglobulin (IVIG) before starting the initial treatment, as these patients may have severe inflammation and vasculitis, which will likely lead to the development of Coronary Artery Lesions (CALs). An intensive initial treatment combined with IVIG and additional anti-inflammatory drugs is reported to reduce the occurrence of IVIG resistance and CALs. Although risk scoring systems using usual laboratory data to predict IVIG-resistant patients have mainly been developed in Japan, these systems did not accurately predict non-responders to IVIG among patients in the other countries. In this review, we provide a comprehensive overview of the main risk scoring systems and evaluate the relevant literature.
\end{abstract}

\section{Introduction}

Kawasaki Disease (KD) is an acute systemic vasculitis that mainly occurs in infants and young children [1]. Although intravenous Immunoglobulin (IVIG) is an effective treatment for KD [2], approximately $10-20 \%$ of KD patients are resistant to IVIG therapy [2,3]. IVIG-resistant patients with KD have a higher risk of developing coronary artery lesions (CALs) than responders to IVIG therapy $[4,5]$. It is important to predict IVIG-resistant KD patients before starting the initial treatment, because intensive initial combination therapy with IVIG and other anti-inflammatory drugs, such as Ulinastatin [6], steroid [7,8] and infliximab [9], may reduce the occurrence of IVIG resistance and/or CALs. There are several risk scoring systems for predicting IVIG resistance in KD patients; the Kobayashi [10], Egami [11] and Sano [12] risk scores have been commonly used in Japan. Recently, we reported a new risk scoring system using two blood cell subtype ratios, the neutrophil-lymphocyte ratio (NLR) and the platelet-to-lymphocyte ratio (PLR) [13]. Furthermore, several researchers have reported other risk scoring systems in such countries as the U.S. [14], Taiwan [15] and China [16-18]. The aim of this review is to compare the predictive validity among these risk scoring systems and assess their problems and limitations.
Risk scoring systems for predicting IVIG resistance in $\mathrm{KD}$

The main risk scoring systems for predicting the IVIG resistance in $\mathrm{KD}$, which have been reported to date, are summarized in Table 1. The parameters of the Egami score [11] consist of alanine aminotransferase (ALT) $\geq 80$ IU/L ( 2 points), age $\leq 6$ months (1 point), days of illness $\leq 4$ days ( 1 point), C-reactive protein (CRP) $\geq 8 \mathrm{mg} / \mathrm{dl}$ ( 1 point) and platelet count $\leq 300 \times 103 / \mathrm{mm} 3$ ( 1 point). In the high-risk group (score $\geq 3$ ), the sensitivity and specificity in the prediction of IVIG resistance were $78 \%$ and $76 \%$, respectively. The parameters of the Sano score [12] consist of Aspartate Amino Transferase (AST) $\geq 200 \mathrm{IU} / \mathrm{L}$ ( 1 point), CRP $\geq 7 \mathrm{mg} / \mathrm{dl}$ (1 point) and total bilirubin $\geq 0.9 \mathrm{mg} / \mathrm{dl}$ (1 point). In the high-risk group (score $\geq 2$ ), the sensitivity and specificity in the prediction of IVIG resistance were $77 \%$ and $86 \%$, respectively. The parameters of the Kobayashi score [10] consist of sodium $\leq 133 \mathrm{mmol} / \mathrm{L}$ ( 2 points), days of illness at initial treatment $\leq 4$ days ( 2 points), AST $\geq 100$ IU/L ( 2 points), $\%$ of neutrophils $\geq 80$ ( 2 points), CRP $\geq 10 \mathrm{mg} / \mathrm{dl}$ ( 1 point), age $\leq 12$ months ( 1 point) and platelet count $\leq 300 \times 103$ / mm3 (1 point). In the high-risk group (score $\geq 4$ ), the sensitivity and specificity in the prediction of IVIG resistance were $86 \%$ and 
$68 \%$, respectively. Recently, Kawamura et al. reported that the combination of NLR $\geq 3.83$ and PLR $\geq 150$ is a useful predictor of IVIG resistance in KD [13], and the sensitivity and specificity of NLR $\geq 3.83$ and PLR $\geq 150$ in the prediction of IVIG resistance were $71 \%$ and $69 \%$, respectively. These simple ratios are convenient and costeffective in comparison to other scoring systems.

Table 1: Risk scoring systems predicting IVIG resistance in KD patients.

\begin{tabular}{|c|c|c|c|c|c|c|c|c|}
\hline Nation & $\begin{array}{l}\text { Scoring } \\
\text { system }\end{array}$ & $\begin{array}{l}\text { No. of KD } \\
\text { patients } \\
\text { enrolled }\end{array}$ & $\begin{array}{c}\text { No. of IVIG } \\
\text {-resistant patients }\end{array}$ & Risk factors & Points & High risk & $\begin{array}{c}\text { Sensitivity } \\
\text { (\%) }\end{array}$ & $\begin{array}{c}\text { Specificity } \\
\text { (\%) }\end{array}$ \\
\hline \multirow{17}{*}{ Japan } & \multirow{5}{*}{ Egami } & \multirow{5}{*}{320} & \multirow{5}{*}{41} & $\mathrm{ALT} \geq 80 \mathrm{IU} / \mathrm{L}$ & 2 & \multirow{5}{*}{$\geq 3$ points } & \multirow{5}{*}{78} & \multirow{5}{*}{76} \\
\hline & & & & Age $\leq 6$ months & 1 & & & \\
\hline & & & & Illness days $\leq 4$ & 1 & & & \\
\hline & & & & $\mathrm{CRP} \geq 8 \mathrm{mg} / \mathrm{dl}$ & 1 & & & \\
\hline & & & & PLT $\leq 300 \times 10^{3} / \mathrm{mm}^{3}$ & 1 & & & \\
\hline & \multirow{3}{*}{ Sano } & \multirow{3}{*}{112} & \multirow{3}{*}{22} & $\mathrm{AST} \geq 200 \mathrm{IU} / \mathrm{L}$ & 1 & \multirow{3}{*}{$\geq 2$ points } & \multirow{3}{*}{77} & \multirow{3}{*}{86} \\
\hline & & & & $\mathrm{CRP} \geq 7 \mathrm{mg} / \mathrm{dl}$ & 1 & & & \\
\hline & & & & $\begin{array}{l}\text { Total bilirubin } \\
\geq 0.9 \mathrm{mg} / \mathrm{dl}\end{array}$ & 1 & & & \\
\hline & \multirow{7}{*}{ Kobayashi } & \multirow{7}{*}{528} & \multirow{7}{*}{148} & Sodium $<133 \mathrm{mmol} / \mathrm{L}$ & 2 & \multirow{7}{*}{$\geq 4$ points } & \multirow{7}{*}{86} & \multirow{7}{*}{68} \\
\hline & & & & Illness days $\leq 4$ & 2 & & & \\
\hline & & & & $\mathrm{AST} \geq 100 \mathrm{IU} / \mathrm{L}$ & 2 & & & \\
\hline & & & & $\%$ of neutrophils $\geq 80$ & 2 & & & \\
\hline & & & & $\mathrm{CRP} \geq 10 \mathrm{mg} / \mathrm{dl}$ & 1 & & & \\
\hline & & & & Age $\leq 12$ months & 1 & & & \\
\hline & & & & PLT $\leq 300 \times 10^{3} / \mathrm{mm}^{3}$ & 1 & & & \\
\hline & \multirow[t]{2}{*}{ Kawamura } & \multirow{2}{*}{405} & \multirow{2}{*}{85} & $N L R \geq 3.83$ & 1 & \multirow{2}{*}{$\geq 2$ points } & \multirow{2}{*}{71} & \multirow{2}{*}{69} \\
\hline & & & & $P L R \geq 150$ & 1 & & & \\
\hline \multirow{4}{*}{ US } & \multirow{4}{*}{ San Giego } & \multirow{3}{*}{362} & \multirow{3}{*}{60} & $\%$ of bands $\geq 20$ & 2 & \multirow{4}{*}{$\geq 2$ points } & \multirow{4}{*}{73} & \multirow{4}{*}{62} \\
\hline & & & & Illness days $\leq 4$ & 1 & & & \\
\hline & & & & $\mathrm{GGT} \geq 60 \mathrm{IU} / \mathrm{L}$ & 1 & & & \\
\hline & & & & $\mathrm{zHgb} \leq-2$ & 1 & & & \\
\hline Taiwan & Formosa & & & $\%$ of neutrophils $\geq 60$ & 2 & & & \\
\hline & & 248 & 29 & Albumin $<3.5 \mathrm{~g} / \mathrm{dl}$ & 1 & $\geq 3$ points & 86 & 81 \\
\hline & & & & $\begin{array}{c}\text { Positive } \\
\text { lymphadenopaty }\end{array}$ & 1 & & & \\
\hline
\end{tabular}




\begin{tabular}{|c|c|c|c|c|c|c|c|c|}
\hline \multirow[t]{16}{*}{ China } & \multirow{5}{*}{$\mathrm{Fu}$} & \multirow{5}{*}{1177} & \multirow{5}{*}{211} & $\%$ of neutrophils $\geq 80$ & 2 & \multirow{5}{*}{$\geq 4$ points } & \multirow{5}{*}{54} & \multirow{5}{*}{71} \\
\hline & & & & Illness days $\leq 4$ & 2 & & & \\
\hline & & & & $\mathrm{CRP} \geq 8 \mathrm{mg} / \mathrm{dl}$ & 2 & & & \\
\hline & & & & $\begin{array}{l}\text { Polymorphous } \\
\text { exanthema }\end{array}$ & 1 & & & \\
\hline & & & & $\begin{array}{r}\text { Change around } \\
\text { the anus }\end{array}$ & 1 & & & \\
\hline & \multirow[t]{5}{*}{ Tang } & \multirow{5}{*}{910} & \multirow{5}{*}{46} & age $<6$ months & 2 & \multirow{5}{*}{$\geq 3$ points } & \multirow{5}{*}{71} & \multirow{5}{*}{76} \\
\hline & & & & Albumin $<3.5 \mathrm{~g} / \mathrm{dl}$ & 2 & & & \\
\hline & & & & Edema of extremities & 1 & & & \\
\hline & & & & Rash & 1 & & & \\
\hline & & & & $\%$ of neutrophils $\geq 80$ & 1 & & & \\
\hline & Hua & \multirow{6}{*}{2126} & \multirow{6}{*}{380} & Fever duration $\geq 7$ days & 2 & \multirow{6}{*}{$\geq 4$ points } & \multirow{6}{*}{61} & \multirow{6}{*}{67} \\
\hline & & & & Delayed diagnosis & 1 & & & \\
\hline & & & & $\mathrm{GGP} \geq 25 \mathrm{U} / \mathrm{L}$ & 1 & & & \\
\hline & & & & Sodium $<135 \mathrm{mmol} / \mathrm{L}$ & 1 & & & \\
\hline & & & & $N L R \geq 2.8$ & 1 & & & \\
\hline & & & & PLT $<350 \times 10^{3} / \mathrm{mm}^{3}$ & 1 & & & \\
\hline
\end{tabular}

ALT, alanine aminotransferase; AST, aspartate aminotransferase; CRP, C-reactive protein; GGT, $\gamma$-glutamyl transferase; NLR, neutrophil-lymphocyte ratio; PLR, platelet to lymphocyte ratio; PLT, platelet; zHgb, age-adjusted hemoglobin concentration.

In the US, the San Diego score [14] was proposed. The parameters consist of $\%$ of bands $\geq 20$ ( 2 point), illness days $\leq 4$ ( 1 point), $\gamma$-glutamyl transferase (GGT) $\geq 60 \mathrm{IU} / \mathrm{L}$ and age-adjusted hemoglobin concentration $(\mathrm{zHgb}) \leq-2$. In the high-risk group (score $\geq 2$ ), the sensitivity and specificity in the prediction of IVIG resistance were $73 \%$ and $62 \%$, respectively. In Taiwan, the Formosa score [15] was reported. The parameters consists of $\%$ of neutrophils $\geq 60$ ( 2 points), albumin $<3.5 \mathrm{~g} / \mathrm{dl}$ ( 1 point) and positive lymphadenopathy ( 1 point). In the high-risk group (score $\geq 3$ ), the sensitivity and specificity in the prediction of IVIG resistance were $86 \%$ and $81 \%$, respectively. In China, Fu et al. reported a scoring system. The parameters consist of $\%$ of neutrophils $\geq 80$ ( 2 points), illness days $\leq 4$ ( 1 point), CRP $\geq 8 \mathrm{mg} / \mathrm{dl}$ ( 2 pint), polymorphous exanthema (1 point) and change around the anus (1 point) [16]. In the high-risk group (score $\geq 4$ ), the sensitivity and specificity in the prediction of IVIG resistance were 54\% and 71\%, respectively. Tang et al. reported another scoring system. The parameters consist of age $<6$ months ( 2 points), albumin $3.5<\mathrm{g} / \mathrm{dl}$ ( 2 points), edema of extremities ( 1 point), rash ( 1 point) and $\%$ of neutrophils $\geq 80$ ( 1 point) [17]. In the high-risk group (score $\geq 3$ ), the sensitivity and specificity in the prediction of IVIG resistance were $71 \%$ and $76 \%$, respectively. Recently, Hua et al. reported a new scoring system. The parameters consist of fever duration $\geq 7$ days ( 2 points), delayed diagnosis (1 point), GGP $\geq 25 \mathrm{mg} / \mathrm{dl}$ (1 point), sodium $<135 \mathrm{mmol} / \mathrm{L}$ (1 point), NLR $\geq 2.8$ ( 1 point) and platelet count $\leq 350 \times 103 / \mathrm{mm} 3$ (1 point) [18]. In the high-risk group (score $\geq 4$ ), the sensitivity and specificity in the prediction of IVIG resistance were $61 \%$ and $67 \%$, respectively. As described above, each of risk scoring systems are determined based on different clinical data and symptoms, although some factors are duplicated among these scoring systems.

\section{Definition of IVIG Resistance}

There are differences in the definition of IVIG resistance in each study. Egami defined IVIG resistance as persistent fever $\left(\geq 37.5^{\circ} \mathrm{C}\right)$ and a fall in CRP by $<50 \%$ within 48 hours after IVIG therapy [11]. Sano defined IVIG resistance as persistent fever $\left(\geq 37.5^{\circ} \mathrm{C}\right.$ over 24 hours) after finishing IVIG therapy [12]. Kobayashi and Kawamura defined IVIG resistance as persistent fever lasting $>24$ hours after the completion of the initial treatment or in the presence of recrudescent fever associated with KD symptoms after an afebrile period [10,13]. The San Diego score defined IVIG resistance as persistent fever $\left(\geq 38.0^{\circ} \mathrm{C}\right.$ rectally or orally) for at least 48 hours but no longer than 7 days after IVIG therapy [14]. The Formosa score defined IVIG resistance as persistent fever or development of recrudescent fever associated with KD symptoms after afebrile period [15]. Fu and Hua defined IVIG resistance as persistent or recrudescent fever at any time 48 hours to 2 weeks after IVIG therapy and at least 1 of the standard diagnostic criteria $[16,18]$. Tang defined IVIG resistance as recrudescent or persistent fever $\geq 36$ hours after the end of IVIG infusion [17]. Thus, because the definition of IVIG resistance has not been standardized, international consensus will be needed in the near future. In the 2017 Kawasaki disease guidelines from the 
American Heart Association, the definition of IVIG resistance was recrudescent or persistent fever at least 36 hours after the end of IVIG infusion [19].

\section{The Application of Risk Scoring Systems to KD Pa- tients in Different Nations}

Several authors have assessed the sensitivity and specificity of risk scoring systems when they were applied to KD patients in the other countries (Table 2). The Kobayashi risk score ( $\geq 4$ ), Egami risk score $(\geq 3)$ and Sano risk score $(\geq 2)$ have good specificity $(87 \%$, $85 \%$ and $85 \%$, respectively) but low sensitivity (33\%, $42 \%$ and $40 \%$, respectively) for predicting IVIG resistance in KD patients in North America [20]. Similarly, the Kobayashi risk score ( $\geq 4)$, Egami risk score ( $\geq 3$ ) and Sano risk score $(\geq 2)$ have good specificity $(87 \%$, $87 \%$ and $92 \%$, respectively) but low sensitivity $(31 \%, 34 \%$ and $28 \%$, respectively) for predicting IVIG resistance in KD patients in Korea [21]. In KD patients in China, Song et al. reported that the
Kobayashi risk score ( $\geq 4)$ and Egami risk score ( $\geq 3$ ) have good specificity ( $85 \%$ and $84 \%$, respectively) but low sensitivity $(16 \%$ and $14 \%$, respectively), the San Diego risk score $(\geq 2)$ has high sensitivity (95\%) but very low sensitivity (3\%), and the Formosa score $(\geq 3)$ has relatively low specificity $(47 \%)$ and sensitivity $(43 \%)$ for predicting IVIG resistance [22]. Qian et al. reported that the sensitivity of Kobayashi risk score ( $\geq 4)$, Egami risk score $(\geq 3)$, Sano risk score $(\geq 2)$, Kawamura risk score $(\geq 2)$ and Formosa score ( $\geq 3$ ) were $72 \%, 44 \%, 20 \%, 48 \%$ and $68 \%$, respectively, and that the specificity of these scores were $62 \%, 82 \%, 91 \%, 66 \%$ and $48 \%$, respectively [23]. In the United Kingdom, the Kobayashi risk score $(\geq 4)$ had relatively low sensitivity (58\%) and low specificity (35\%) [24]. In the Kobayashi score, a cut-off risk score of 5 points was also reported to be effective for predicting IVIG resistance in Japanese patients with $\mathrm{KD}[7,25]$. The Kobayashi risk score $(\geq 5)$ is reported to predict IVIG resistance in Iranian patients with $\mathrm{KD}$, with $50 \%$ sensitivity and $94 \%$ specificity [26].

Table 2: Sensitivity and Specificity of risk scoring systems when applied to different ethnic group.

\begin{tabular}{|c|c|c|c|c|c|c|}
\hline Nation & Authors & $\begin{array}{l}\text { No. of KD patients } \\
\text { enrolled }\end{array}$ & $\begin{array}{c}\text { No. of IVIG } \\
\text {-resistant patients }\end{array}$ & $\begin{array}{l}\text { Scoring } \\
\text { system }\end{array}$ & $\begin{array}{c}\text { Sensitivity } \\
\text { (\%) }\end{array}$ & $\begin{array}{c}\text { Specificity } \\
\text { (\%) }\end{array}$ \\
\hline \multirow{3}{*}{ U.S. } & \multirow{3}{*}{ Sleeper } & 71 & 9 & Kobayashi $(\geq 4)$ & 33 & 87 \\
\hline & & 90 & 12 & Egami ( $\geq 3$ ) & 42 & 85 \\
\hline & & 66 & 10 & Sano $(\geq 2)$ & 40 & 85 \\
\hline \multirow{3}{*}{ Korea } & \multirow{3}{*}{ Kim } & 703 & 118 & Kobayashi $(\geq 4)$ & 31 & 87 \\
\hline & & & & Egami $(\geq 3$ ) & 34 & 87 \\
\hline & & & & Sano $(\geq 2)$ & 28 & 92 \\
\hline \multirow{9}{*}{ China } & \multirow{4}{*}{ Song } & 1163 & 63 & Kobayashi $(\geq 4)$ & 16 & 85 \\
\hline & & & & Egami ( $\geq 3$ ) & 14 & 84 \\
\hline & & & & San Diego $(\geq 2)$ & 95 & 3 \\
\hline & & & & Formosa $(\geq 3$ ) & 43 & 47 \\
\hline & \multirow{5}{*}{ Qian } & 504 & 25 & Kobayashi $(\geq 4)$ & 72 & 62 \\
\hline & & & & Egami $(\geq 3)$ & 44 & 82 \\
\hline & & & & Sano $(\geq 2)$ & 20 & 91 \\
\hline & & & & Kawamura $(\geq 2)$ & 48 & 66 \\
\hline & & & & Formosa ( $\geq 3$ ) & 68 & 48 \\
\hline U.K. & Davies & 59 & 19 & Kobayashi $(\geq 4)$ & 58 & 35 \\
\hline Iran & Nateghian & 97 & 19 & Kobayashi $(\geq 5)$ & 50 & 94 \\
\hline \multirow{3}{*}{ German } & \multirow{3}{*}{ Jakob } & 301 & 47 & Kobayashi $(\geq 4)$ & 43 & 83 \\
\hline & & & & Egami ( $\geq 3$ ) & 49 & 76 \\
\hline & & & & Sano $(\geq 2)$ & 28 & 94 \\
\hline \multirow{3}{*}{ Italy } & \multirow{3}{*}{ Fabi } & 257 & 43 & Kobayashi $(\geq 4)$ & 64 & 63 \\
\hline & & & & Egami ( $\geq 3$ ) & 41 & 77 \\
\hline & & & & Formosa ( $\geq 3$ ) & 71 & 45 \\
\hline
\end{tabular}


Recently, Jakob et al. reported that the Kobayashi risk score $(\geq 4)$, Egami risk score $(\geq 3)$ and Sano risk score $(\geq 2)$ have low sensitivity (43\%, 49\% and $28 \%$, respectively), although they have relatively high specificity (83\%, 76\% and 94\%, respectively), in German patients with KD [27]. More recently, Fabi et el. reported that the Kobayashi risk score $(\geq 4)$, Egami risk score $(\geq 3)$ and Formosa score $(\geq 3)$ are ineffective for predicting IVIG resistance (sensitivity: $64 \%, 41 \%$ and $71 \%$, respectively; specificity: $63 \%, 77 \%$ and $45 \%$, respectively) in Italian children with KD [28]. Besides, the ability of NRL and PLR to predict IVIG resistance in KD was evaluated in China: the cut-off values of NLR $\geq 4.36$ and PLR $\geq 162$ were useful for predicting IVIG-resistance in KD [29], and NLR $\geq 2.51$ was useful in KD patients younger than 1 year of age [30]. Although there is a slight difference in the cut-off values of Japan [13] and China [29], the effectiveness of the NLR and PLR in predicting IVIG resistance has been proven in both countries.

\section{Problems and Limits of Risk Scoring Systems for IVIG Resistance in KD}

Many of the Japanese scoring systems (Egami, Sano and Kobayashi scores) had relatively good specificity but low sensitivity when they were applied to non-Japanese KD patients. These results indicate that the use of Japanese risk scores in other countries can exclude most patients who do not require additional therapy (lowrisk patients) but cannot accurately extract patients who require additional therapies (high-risk patients). For this reason, these Japanese risk scores have not been widely used outside Japan. These regional differences could be due to genetic differences or other environmental factors [31]. It is reported that the functional polymorphism and methylation of the immunoglobulin gamma Fc region receptor II-a (FCGR2A) gene might be associated with IVIG resistance in KD patients [32,33]. As there is a difference in the incidence of KD among countries, the disease severity and the effectiveness of IVIG therapy might also be different. It seems difficult to establish a universal risk scoring system for IVIG resistance in KD due to racial differences. Thus, it might be better to aim to establish discrete risk scoring systems for each country. It would be preferable if the risk score is simple and convenient. The determination of cut-off values for the NLR and PLR in each country may warrant investigation because these ratios are easily calculated. In summary, the prediction of failure to respond to IVIG therapy is important for identifying KD patients who may need additional anti-inflammatory treatments, because intensive therapy can be reduce the incidence of IVIG resistance and CAL formation. Although several risk scoring systems of IVIG resistance have been proposed, many of these failed to effectively predict IVIG resistance in other countries. Further studies will be needed to obtain consensus on a risk scoring system for predicting IVIG resistance in $\mathrm{KD}$.

\section{References}

1. Kawasaki T, Kosaki F, Shigematsu I, Yanagawa H (1974) A new infantile acute febrile mucocutaneous lymph node syndrome (MLNS) prevailing in Japan. Pediatrics 54(3): 271-276.
2. Newburger JW, Takahashi M, Beiser AS, Burns JC, Bastian J, Chung KJ, et al. (1991) A single intravenous infusion of gamma globulin as compared with four infusions in the treatment of acute Kawasaki syndrome. New Engl J Med 324(23): 1633-1639.

3. Nakamura Y, Yashiro M, Uehara R, Sadakane A, Tsuboi S, Aoyama Y, et al. ( 2012) Epidemiologic features of Kawasaki disease in Japan: results of the 2009-2010 nationwide survey. J Epidemiol 22(3): 216-221.

4. Tremoulet AH, Best BM, Song S, Wang S, Corinaldesi E, et al. (2008) Resistance to intravenous immunoglobulin in children with Kawasaki disease. J Pediatr 153(1): 117-121.

5. Muta H, Ishii M, Furui J, Nakamura Y, Matsuishi T (2006) Risk factors associated with the need for additional intravenous gamma-globulin therapy for Kawasaki disease. Acta Paediatr 95(2): 189-193.

6. Kanai T, Ishiwata T, Kobayashi T, Sato H, Takizawa M, et al. (2011) Ulinastatin, a urinary trypsin inhibitor, for the initial treatment of patients with Kawasaki disease: a retrospective study. Circulation 124(25): 2822-2828

7. Kobayashi T, Saji T, Otani T, Takeuchi K, Nakamura T, et al. (2012) Efficacy of immunoglobulin plus prednisolone for prevention of coronary artery abnormalities in severe Kawasaki disease (RAISE study): a randomised, open-label, blinded-endpoints trial. Lancet 379(9826): 1613-1620.

8. Ogata S, Ogihara Y, Honda T, Kon S, Akiyama K, et al. (2012) Corticosteroid pulse combination therapy for refractory Kawasaki disease: A randomized trial. Pediatrics 129(1):e17-23.

9. Tremoulet $\mathrm{AH}$, Jain S, Jaggi P, Jimenez-Fernandez S, Pancheri, et al. (2014) Infliximab for intensification of primary therapy for Kawasaki disease: a phase 3 randomised, double-blind, placebo-controlled trial. Lancet 383(9930): 1731-1738.

10. Kobayashi T, Inoue Y, Takeuchi K, Okada Y, Tamura K, et al. (2006) Prediction of intravenous immunoglobulin unresponsiveness in patients with Kawasaki disease. Circulation 113(22): 2606-2612.

11. Egami K, Muta H, Ishii M, Suda K, Sugahara Y, et al (2006) Prediction of resistance to intravenous immunoglobulin treatment in patients with Kawasaki disease. J Pediatr 149(2): 237-40.

12. Sano T, Kurotobi S, Matsuzaki K, Yamamoto T, Maki I, et al. (2007) Prediction of non-responsiveness to standard high-dose gammaglobulin therapy in patients with acute Kawasaki disease before starting initial treatment. Eur J Pediatr 166(2): 131-137.

13. Kawamura Y, Takeshita S, Kanai T, Yoshida Y, Nonoyama S (2016) The Combined Usefulness of the Neutrophil-to-Lymphocyte and Plateletto-Lymphocyte Ratios in Predicting Intravenous Immunoglobulin Resistance with Kawasaki Disease. J Pediatr 178: 281-284.

14. Tremoulet AH, Best BM, Song S, Wang S, Corinaldesi E, et al. (2008) Burns JC. Resistance to intravenous immunoglobulin in children with Kawasaki disease. J Pediatr 153(1): 117-121.

15. Lin MT, Chang CH, Sun LC, Liu HM, Chang HW, et al. (2016) Risk factors and derived formosa score for intravenous immunoglobulin unresponsiveness in Taiwanese children with Kawasaki disease. J Formos Med Assoc. 115(5): 350-355.

16. Fu PP, Du ZD, Pan YS (2013) Novel predictors of intravenous immunoglobulin resistance in Chinese children with Kawasaki disease. Pediatr Infect Dis J 32(8): e319-323.

17. Tang Y, Yan W, Sun L, Huang J, Qian W, et al. 2016) Prediction of intravenous immunoglobulin resistance in Kawasaki disease in an East China population. Clin Rheumatol 35(11): 2771-2776.

18. Hua W, Sun Y, Wang Y, Fu S, Wang W, et al. (2017) A new model to predict intravenous immunoglobin-resistant Kawasaki disease. Oncotarget 19(8): 80722-80729.

19. McCrindle BW, Rowley AH, Newburger JW, Burns JC, Bolger AF (2017) Diagnosis, Treatment, and Long-Term Management of Kawasaki Disease: 
A Scientific Statement for Health Professionals From the American Heart Association. Circulation. 135(17): e927-e999

20. Sleeper LA, Minich LL, McCrindle BM, Li JS, Mason W, et al. (2011) Evaluation of Kawasaki disease risk-scoring systems for intravenous immunoglobulin resistance. J Pediatr 158(5): 831-835.

21. Kim BY, Kim D, Kim YH, Ryoo E, Sun YH, et al. (2016) Non-Responders to Intravenous Immunoglobulin and Coronary Artery Dilatation in Kawasaki Disease: Predictive Parameters in Korean Children. Korean Circ J. 46(4): 542-549.

22. Song R, Yao W, Li X (2017) Efficacy of Four Scoring Systems in Predicting Intravenous Immunoglobulin Resistance in Children with Kawasaki Disease in a Children's Hospital in Beijing, North China. J Pediatr. 1840: 120-124.

23. Qian W, Tang Y, Yan W, Sun L, Lv HA (2018)comparison of efficacy of six prediction models for intravenous immunoglobulin resistance in Kawasaki disease. Ital J Pediatr 44(1): 33.

24. Davies S, Sutton N, Blackstock S, Gormley S, Hoggart CJ, et al. (2015) Predicting IVIG resistance in UK Kawasaki disease. Arch Dis Child 100(4): 366-368.

25. Seki M, Kobayashi T, Kobayashi T, Morikawa A, Otani T, et al. (2011) External validation of a risk score to predict intravenous immunoglobulin resistance in patients with kawasaki disease. Pediatr Infect Dis J 30(2): 145-147.

26. Nateghian A, Tafreshi RI, Najari A, Vaezi A (2016) The validity of a scoring system in predicting intravenous immunoglobulin treatment failure in children with Kawasaki disease. Arch Pediatr Infect Dis. 4(1): e27527.
27. Jakob A, von Kries R, Horstmann J, Hufnagel M, Stiller B, et al. (2018) Failure to Predict High-risk Kawasaki Disease Patients in a Populationbased Study Cohort in Germany. Pediatr Infect Dis J 37(9): 850-855.

28. Fabi M, Andreozzi L, Corinaldesi E, Bodnar T, Lami F, et al. (2019) Inability of Asian risk scoring systems to predict intravenous immunoglobulin resistance and coronary lesions in Kawasaki disease in an Italian cohort. Eur J Pediatr 178(3): 315-322.

29. Yuan YD, Sun J, Li PF, Wei CL, Yu YH (2017) Values of neutrophillymphocyte ratio and platelet-lymphocyte ratio in predicting sensitivity to intravenous immunoglobulin in Kawasaki disease. Chinese Journal of Contemporary Pediatrics. 19(4): 410-413.

30. Chen Y, Hua Y, Zhang C, Chen S, Zhang Q, et al. (2019) Neutrophil-tolymphocyte ratio predicts intravenous immunoglobulin-resistance in infants under 12-months old with Kawasaki disease. Front Pediatr. 7: 81.

31. Rigante D, Andreozzi L, Fastiggi M, Bracci B, Natale MF, Esposito S (2016) Critical Overview of the Risk Scoring Systems to Predict NonResponsiveness to Intravenous Immunoglobulin in Kawasaki Syndrome. Int J Mol Sci 17(3): 278.

32. Khor CC, Davila S, Breunis WB, Lee YC, Shimizu C, et al. (2011) Genomewide association study identifies FCGR2A as a susceptibility locus for Kawasaki disease. Nat Genet 43(12): 1241-1246.

33. Kuo HC, Chang JC, Kuo HC, Yu HR, Wang CL, et al. (2015) Identification of an association between genomic hypomethylation of FCGR2A and susceptibility to Kawasaki disease and intravenous immunoglobulin resistance by DNA methylation array. Arthritis Rheumatol 67(3): 828836.

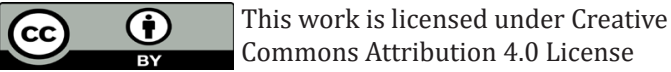

To Submit Your Article Click Here: Submit Article

DOI: $10.32474 /$ ACR.2019.02.000142

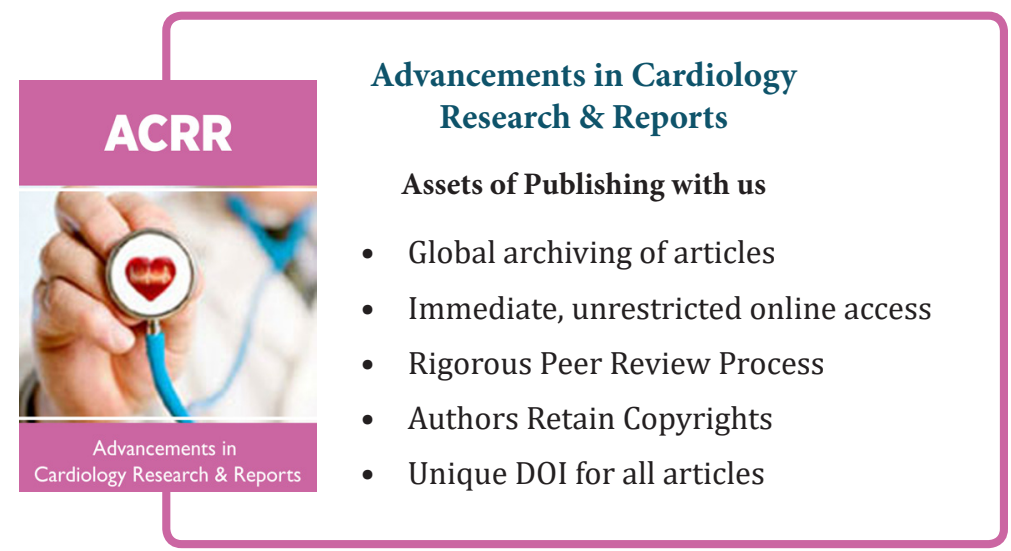

